\title{
The metabolic syndrome of fructose-fed rats: Effects of long-chain polyunsaturated $\omega 3$ and $\omega 6$ fatty acids. II. Time course of changes in food intake, body weight, plasma glucose and insulin concentrations and insulin resistance
}

\author{
ZOHEIR MELLOUK ${ }^{1}$, TAREK HACHIMI IDRISSI ${ }^{2}$, KARIM LOUCHAMI $^{2}$, EMELINE HUPKENS $^{2}$, \\ ABDULLAH SENER $^{2}$, DALILA AIT YAHIA ${ }^{1}$ and WILLY J. MALAISSE ${ }^{2}$ \\ ${ }^{1}$ Department of Biology, Es-Sénia University, Oran, Algeria; ${ }^{2}$ Laboratory of Experimental \\ Hormonology, Université Libre de Bruxelles, Brussels, Belgium
}

Received July 6, 2011; Accepted August 22, 2011

DOI: 10.3892/ijmm.2011.789

\begin{abstract}
The time course for changes in food intake, body weight, plasma glucose and insulin concentrations and HOMA index was monitored over a period of 8 weeks in rats exposed from the 8th week after birth to diets containing either starch or fructose and sunflower oil. In two further groups of rats exposed to the fructose-rich diet part of the sunflower oil was substituted by either salmon oil rich in long-chain polyunsaturated $\omega 3$ fatty acids or safflower oil rich in long-chain polyunsaturated $\omega 6$ fatty acids. Despite lower food intake, the gain in body weight was higher in fructose-fed rats than in starch-fed rats. The supplementation of the fructose-rich diet by either $\omega 3$ or $\omega 6$ fatty acids lowered both food intake and body weight gain. The measurements of plasma glucose and insulin concentrations, HOMA index and insulinogenic index performed after overnight starvation were in fair agreement with those recorded at the occasion of an intraperitoneal glucose tolerance test, with higher values for plasma glucose concentration and HOMA index in the fructose-fed rats exposed to the sunflower oil (with or without enrichment with $\omega 6$ fatty acids) than in the starch-fed rats exposed to the sunflower oil or fructose-fed rats exposed to a diet enriched with $\omega 3$ fatty acids. Such was also the case for the measurements of glycated albumin at sacrifice. Moreover, the insulinogenic index was lower in the fructose-fed rats with or without dietary enrichment in $\omega 6$ fatty acids than in the fructose-fed rats with
\end{abstract}

Correspondence to: Professor Willy J. Malaisse, Laboratory of Experimental Hormonology, Université Libre de Bruxelles, 808 Route de Lennik, B-1070 Brussels, Belgium

E-mail:malaisse@ulb.ac.be

Key words: metabolic syndrome, fructose-fed rats, long-chain polyunsaturated $\omega 3$ and $\omega 6$ fatty acids, food intake, body weight, plasma glucose and insulin concentrations, HOMA index dietary enrichment in $\omega 3$ fatty acids. The elucidation of the biochemical determinants of the later difference requires further investigations in isolated pancreatic islets.

\section{Introduction}

In the first report in this series, attention was drawn to the plasma D-glucose and insulin concentration, insulinogenic index and HOMA index for insulin resistance found during an intraperitoneal glucose tolerance test conducted in rats first exposed for 50 days to either a control diet containing $64 \%$ (w/w) starch and 5\% (w/w) sunflower diet, or a diet in which starch was substituted by an equal amount of D-glucose (1). Two further groups of rats were exposed to the latter fructosecontaining diet, but with $1.6 \%$ (w/w) of sunflower diet being substituted by an equal amount of either salmon oil rich in polyunsaturated $\omega 3$ fatty acids or C18:2 $\omega 6$-rich safflower oil. The present report deals mainly with the time course of changes in food intake, body weight, plasma D-glucose and insulin concentrations, as well as insulinogenic and HOMA indices recorded over an 8-week period of exposure to these four diets. Further variables, including the weight of parametrial and visceral adipose tissue, liver, kidney, heart and soleus muscle, glycated hemoglobin and plasma albumin and D-glucose concentrations were also measured at sacrifice after overnight starvation.

\section{Materials and methods}

The experimental design, the food composition, the methods for measuring plasma D-glucose and insulin concentrations and the procedure for statistical analysis were already detailed in the first report in this series (1). Food intake was measured daily in groups of 5-6 rats each. Body weight was recorded at weekly intervals. Plasma samples were collected by retroorbital route after overnight starvation. At sacrifice blood was sampled by cardiac puncture in anesthetized rats. The methods used for the measurement of glycated hemoglobin (Tina Quant HbAlc; Roche Diagnostics, Meylan, France), plasma D-fructose (2) and 

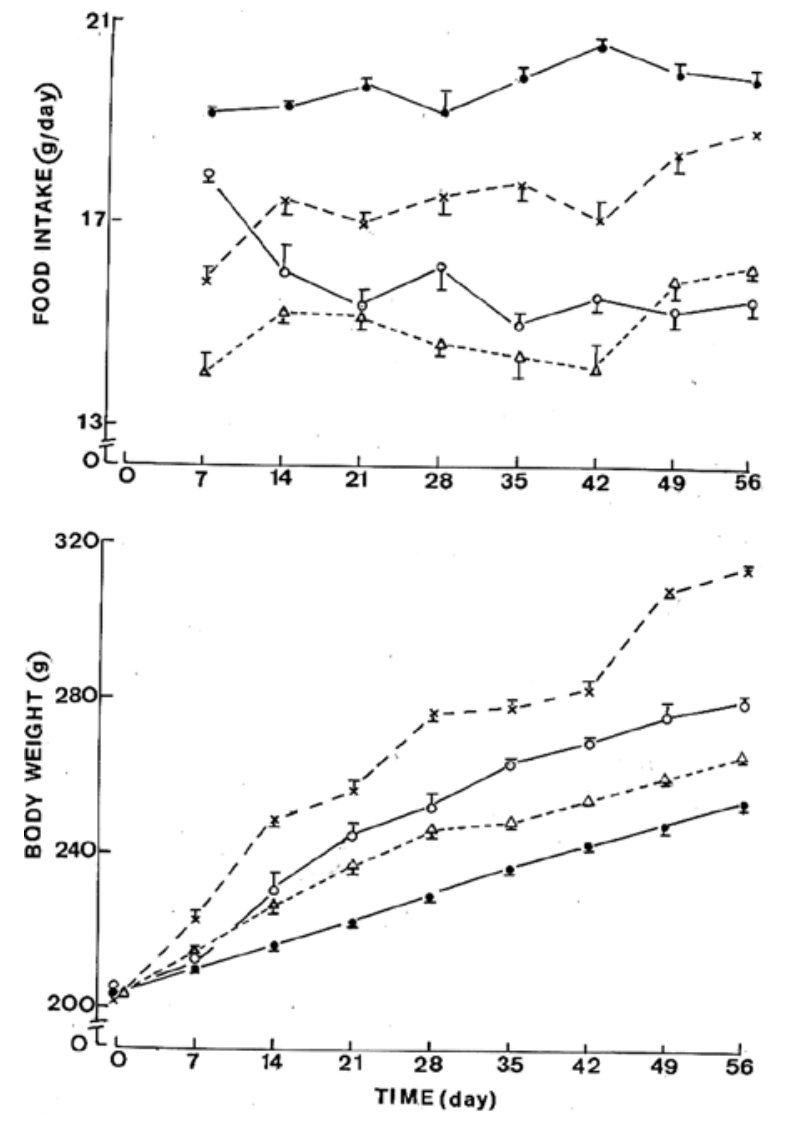

Figure 1. Time course for the changes in food intake (upper panel) and body weight (lower panel) in (Ssun) rats (closed circles and solid line), (Fsun) rats (crosses and dashed line), (Fsal) rats (open circles and solid line) and (Fsaf) rats (open triangles and dotted line). Mean values ( \pm SEM) refer to 7-10 successive measurements made over periods of 7-10 days in the case of food intake, and to 5-6 measurements in the case of body weight.

albumin (Albumin Bromcresol green; Spinreact, Sant Esteve de Bas, Spain) concentrations are described in the cited references. For the measurement of D-fructose, its phosphorylation by hexokinase was preceded by the treatment of the samples by glucose oxidase.

\section{Results}

Food intake and body weight. The time course for the daily food intake over the 56 days of the present experiments is illustrated in Fig. 1 (upper panel). Over this period, it averaged $19.7 \pm 0.1 \mathrm{~g}(\mathrm{n}=56)$ in (Ssun) rats, as distinct from $17.5 \pm 0.2 \mathrm{~g}$ $(\mathrm{n}=57)$ in the (Fsun) rats, $15.9 \pm 0.2 \mathrm{~g}(\mathrm{n}=59)$ in the (Fsal) rats, and $15.0 \pm 0.1 \mathrm{~g}(\mathrm{n}=58)$ in the (Fsaf) rats. All these mean values differed significantly $(\mathrm{p}<0.001)$ from one another. A somewhat different hierarchy prevailed during the first week of the present experiments, with mean values for daily food intake of $19.2 \pm 0.1 \mathrm{~g}(\mathrm{n}=7)$ in the (Ssun) rats, $18.0 \pm 0.2 \mathrm{~g}(\mathrm{n}=7)$ in the (Fsal) rats, $15.8 \pm 0.3 \mathrm{~g}(\mathrm{n}=7)$ in the (Fsun) rats, and $14.0 \pm 0.4 \mathrm{~g}$ $(n=7)$ in the (Fsaf) rats. Thus, these early measurements of food intake, which all again differed significantly from one another ( $<<0.025$ or less) documented a lower food intake in the fructose-fed animals than in the (Ssun) rats, such a difference being least pronounced in the (Fsal) rats and most pronounced in the (Fsaf) rats.
Table I. Food intake and body weight.

\begin{tabular}{lccc}
\hline Rats & Food intake & \multicolumn{2}{c}{ Body weight } \\
\cline { 3 - 4 } & $(\mathrm{g} / \text { day per rat })^{\mathrm{a}}$ & Time zero $(\mathrm{g})$ & Relative gain $(\%)^{\mathrm{a}}$ \\
\hline Ssun & $19.7 \pm 0.1(56)$ & $203.9 \pm 1.8(6)$ & $24.6 \pm 0.7(6)$ \\
Fsun & $17.5 \pm 0.2(57)$ & $201.4 \pm 3.7(6)$ & $56.2 \pm 3.5(6)$ \\
Fsal & $15.9 \pm 0.2(59)$ & $204.8 \pm 2.5(6)$ & $37.9 \pm 1.8(5)$ \\
Fsaf & $15.0 \pm 0.1(58)$ & $203.9 \pm 2.1(6)$ & $30.6 \pm 1.5(6)$ \\
\hline
\end{tabular}

${ }^{\mathrm{a}}$ Measurements computed over a 56 days period.

The initial mean body weight was virtually identical in the 4 groups of rats (Table I). Already during the first week of the present experiments, the relative gain in body weight was significantly higher $(\mathrm{p}<0.001)$ in the (Fsun) rats $(+10.7 \pm 1.0 \%$; $n=6)$ than in the other animals $(+4.1 \pm 0.5 \%$; $=18)$. Over the entire period of 56 days, such a relative gain in body weight averaged $56.2 \pm 3.5 \%(\mathrm{n}=6)$ in the (Fsun) rats as distinct $(\mathrm{p}<0.003$ or less) from $24.6 \pm 0.7 \%(\mathrm{n}=6)$ in the (Ssun) rats, $30.6 \pm 1.5 \%$ $(\mathrm{n}=6)$ in the (Fsaf) rats and $37.9 \pm 1.8 \%(\mathrm{n}=5)$ in the (Fsal) rats.

The apparent caloric efficiency of the diet, as judged from the ratio between the relative increase in body weight and mean value for daily food intake, both computed over the 8 weeks of the present experiments, followed a comparable hierarchy as that just mentioned for the relative gain in body weight with mean values of $1.25 \pm 0.02$ in the (Ssun) rats, $3.21 \pm 0.10$ in the (Fsun) rats, $2.39 \pm 0.09$ in the (Fsal) rats and $2.04 \pm 0.07$ in the (Fsaf) rats.

Organ weight at sacrifice. The wet weight of the parametrial adipose tissue, visceral adipose tissue collected along the intestinal tract, liver, kidney, heart and soleus muscles are listed in Table II. Unexpectedly, the mean values for parametrial and visceral adipose tissue were, as a rule, lower in fructose-fed rats than in (Ssun) rats. Such a difference achieved statistical significance $(\mathrm{p}<0.025)$ when comparing the measurements of both parametrial and visceral adipose tissue made in (Ssun) and (Fsun) rats. The liver wet weight, however, was higher ( $p<0.05$ or less) in each group of fructose-fed rats than in (Ssun) rats. Such was also the case ( $<<0.025$ or less) for the kidney weight. Last, in the case of heart and soleus muscles, no significant difference was observed between the four groups of rats. Such distinct situations are illustrated in Fig. 2.

Plasma glucose concentrations. Before the start of the experiments, the plasma glucose concentration averaged $6.85 \pm 0.51 \mathrm{mM}(\mathrm{n}=24)$.

In the (Ssun) animals, the plasma glucose concentration averaged, over the entire period after the start of the experiments $98.7 \pm 5.2 \%(n=36)$ of the mean corresponding value recorded at time zero of such experiments.

In the (Fsal) rats, a somewhat higher value $(\mathrm{p}<0.02)$ was observed over the entire period after the start of the experiments, the plasma glucose concentration averaging $123.6 \pm 8.7 \%(\mathrm{n}=34)$ of the mean corresponding zero time value. Such a difference 
Table II. Organ weight at sacrifice.

\begin{tabular}{lcccc}
\hline Rats & Ssun & Fsun & Fsal & Fsaf \\
\hline Parametrial adipose tissue (g) & $8.26 \pm 1.04(6)$ & $6.27 \pm 0.75(6)$ & $7.25 \pm 1.24(5)$ & $7.31 \pm 1.34(6)$ \\
Visceral adipose tissue (g) & $8.65 \pm 1.13(6)$ & $6.38 \pm 0.70(6)$ & $8.72 \pm 1.65(5)$ & $7.63 \pm 1.02(6)$ \\
Liver (g) & $6.85 \pm 0.19(6)$ & $8.07 \pm 0.23(6)$ & $7.89 \pm 0.45(5)$ & $8.24 \pm 0.28(6)$ \\
Kidney (mg) & $897 \pm 16(12)$ & $1,136 \pm 45(12)$ & $1,073 \pm 52(10)$ & $985 \pm 32(12)$ \\
Heart (mg) & $838 \pm 39(6)$ & $860 \pm 32(6)$ & $819 \pm 55(5)$ & $859 \pm 20(6)$ \\
Soleus muscles (mg) & $250 \pm 12(6)$ & $270 \pm 8(6)$ & $245 \pm 16(5)$ & $278 \pm 6(6)$ \\
\hline
\end{tabular}
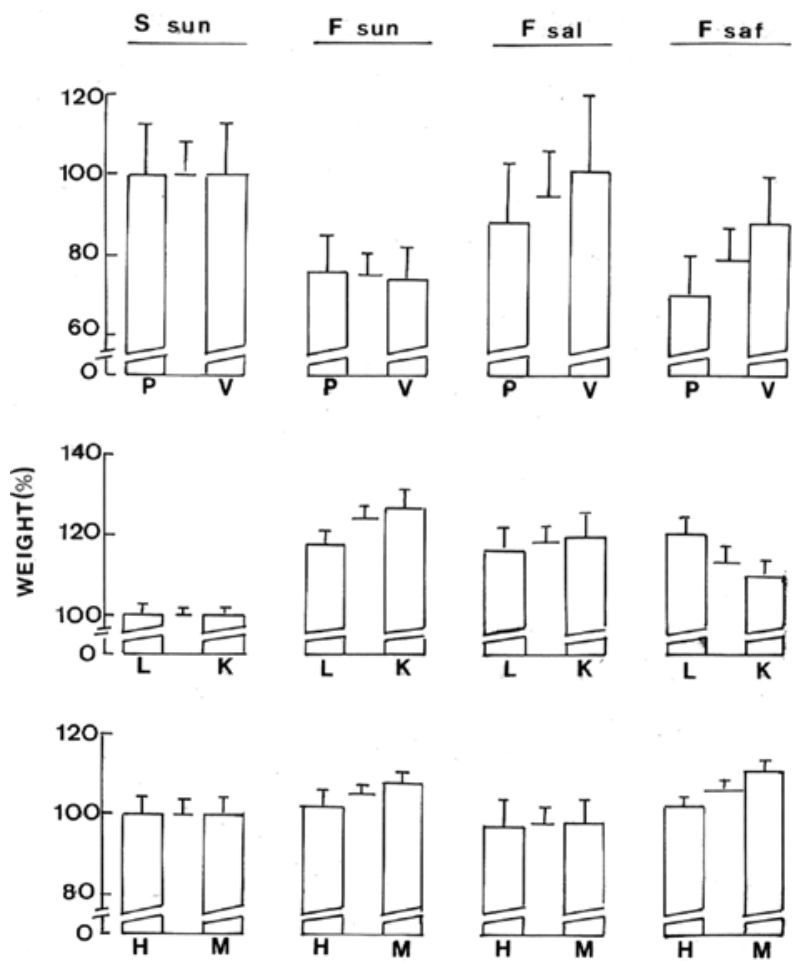

Figure 2. Wet weight of parametrial (P) and visceral (V) adipose tissue in upper panel, liver (L) and kidney $(\mathrm{K})$ in middle panel, and heart $(\mathrm{H})$ and soleus muscles (M) in lower panel obtained from (Ssun), (Fsun), (Fsal) and (Fsaf) rats. All results are expressed relative to the mean corresponding value found in (Ssun) rats. Mean values $( \pm$ SEM) refer to 5-6 $(\mathrm{P}, \mathrm{V}, \mathrm{L}, \mathrm{H}$ and $\mathrm{M}$ ) or 10-12 (K) separate measurements. The horizontal lines shown between each pair of columns refer to the overall mean values derived from all measurements made in the two organs under consideration.

was most pronounced during the first weeks (Fig. 3). Thus, always considered by comparison with the zero time value, the readings made in the (Fsal) rats expressed relative to those found at the same time in the (Ssun) rats progressively decreased from $147.6 \pm 15.3 \%(n=6)$ at day 7 to $96.4 \pm 6.3 \%(n=5)$ at sacrifice. According to the same analytical procedure, the values recorded in the former rats decreased $(\mathrm{p}<0.05)$ from $133.1 \pm 6.9 \%(\mathrm{n}=18)$ between day 7 and day 21 to $114.6 \pm 5.7 \%$ between day 28 and sacrifice. The latter two percentages remained higher $(\mathrm{p}<0.02$ or less) than the corresponding reference value recorded in the control animals, i.e. $100.0 \pm 3.2 \%(n=18)$ and $100.0 \pm 1.5 \%$ $(\mathrm{n}=18)$. The mean absolute values $(\mathrm{mM})$ for plasma glucose concentrations were never significantly different, however, from those recorded at the same time in the (Ssun) rats.

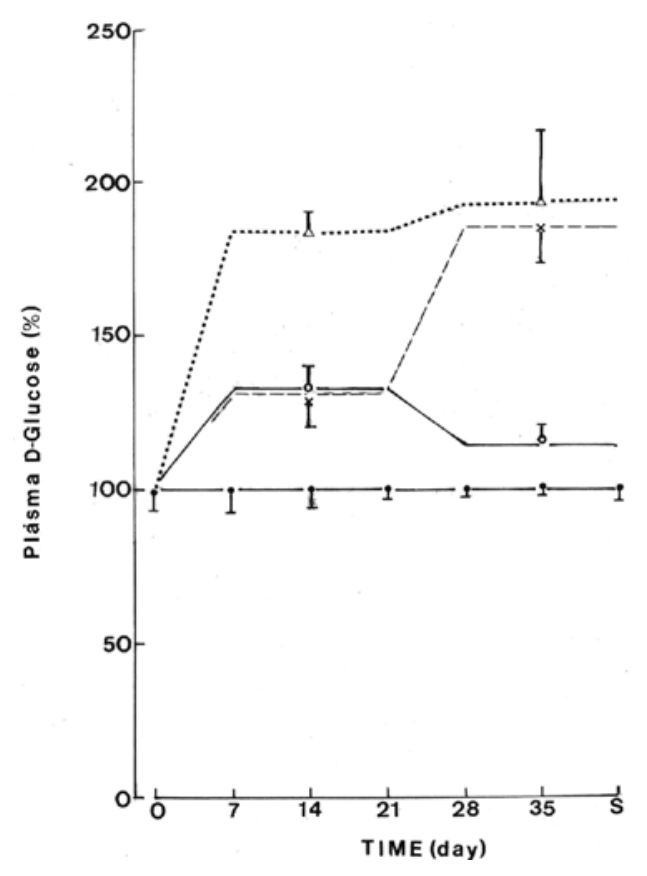

Figure 3. Time course for the changes in plasma D-glucose concentration between day zero and sacrifice (S) in (Ssun) rats (closed circles and solid line), (Fsun) rats (crosses and dashed line), (Fsal) rats (open circles and solid line) and (Fsaf) rats (open triangles and dotted line). All results, expressed relative to the corresponding mean value found at time zero in the same group of rats are shown relative to the mean value recorded at the same time in the (Ssun) rats. Mean values ( \pm SEM) refer to 6 individual measurements made at each time point in (Ssun) rats, and 16-18 measurements made over successive periods of three weeks each in the fructose-fed animals.

In the (Fsun) rats, the plasma glucose concentration averaged over the entire period after the start of the experiments $146.5 \pm 7.0 \%(n=36)$ of the mean corresponding zero time value, being thus significantly higher $(\mathrm{p}<0.05)$ than that recorded in the (Fsal) rats $(123.6 \pm 8.7 \% ; n=34)$. In the (Fsun) animals, the plasma glucose concentration, expressed relative to the mean corresponding zero time values, averaged between day 14 and sacrifice, $174.2 \pm 7.8 \%(n=30)$ of the corresponding values found at the same time in (Ssun) rats $(100.0 \pm 1.6 \% ; n=30)$, as compared $(\mathrm{p}<0.001)$ to no more than $119.4 \pm 4.3 \%(\mathrm{n}=28)$ in the (Fsal) rats. Likewise, between day 14 and sacrifice, the mean absolute values for plasma glucose concentration were higher $(\mathrm{p}<0.001)$ in the (Fsun) rats than in the (Fsal) rats, the values recorded in the former animals averaging $121.2 \pm 5.0 \%$ $(n=30)$ of the mean corresponding values found at the same time in the latter rats $(100.0 \pm 3.0 \% ; \mathrm{n}=28)$. 


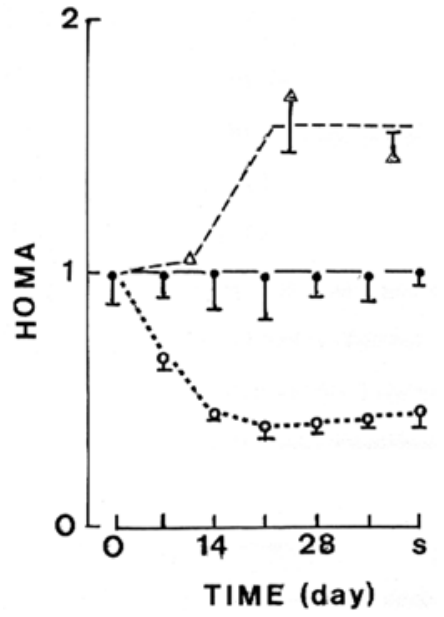

Figure 4. Time course between day zero and sacrifice (S) for the HOMA in the (Fsal) rats (open circles and dotted line) and in both the (Fsun) and (Fsaf) rats (open triangles and dashed line). All results are expressed relative to the mean corresponding zero time value and shown relative to the measurements recorded at the same time in the (Ssun) rats (closed circles and solid line). Mean values ( \pm SEM) refer to 5-6 (closed and open circles) and 24 (open triangles) individual determinations.

Last, in the (Fsaf) rats, the plasma glucose concentrations averaged over the entire period after the start of the experiments $183.2 \pm 12.6 \%(n=36)$ of the mean corresponding zero time value, thus exceeding $(\mathrm{p}<0.02)$ that recorded in the (Fsun) rats $(146.5 \pm 7.0 \% ; \mathrm{n}=30)$. Such a difference was most marked at day 7 and progressively faded out, thereafter. Indeed, relative to the mean values for the plasma glucose concentration, all expressed relative to the corresponding mean zero time values, recorded at the same time in the (Fsun) rats, those collected in the (Fsaf) rats averaged $229.9 \pm 6.9 \%(\mathrm{n}=6)$ on day $7,122.2 \pm 13.8 \%(\mathrm{n}=6)$ on day $14,113.6 \pm 1.7 \%(\mathrm{n}=6)$ on day 21 , and $104.6 \pm 10.3 \%(\mathrm{n}=18)$ between day 28 and sacrifice. The mean absolute values $(\mathrm{mM})$ for plasma glucose concentrations over the entire period after the start of the experiments were also higher $(\mathrm{p}<0.004)$ in the (Fsaf) rats than in (Fsun) rats, averaging in the former rats $130.3 \pm 9.5 \%(\mathrm{n}=36)$ of the mean corresponding values recorded at the same time in the latter animals $(100.0 \pm 2.6 \% ; \mathrm{n}=36)$.

Plasma insulin concentrations. Before the start of the experiments, the plasma insulin concentration averaged $64 \pm 4 \mu \mathrm{U} / \mathrm{ml}$ $(\mathrm{n}=24)$.

In the (Ssun) rats, the mean value recorded during the experiments did not differ significantly ( $>0.53$ ) from that prevailing at time zero.

In the (Fsal) rats, the insulin concentration expressed relative to the corresponding mean zero time value, represented between day 7 and sacrifice about half $(42.5 \pm 1.6 \% ; n=34)$ of the corresponding values found at the same time in the control animals $(100.0 \pm 3.6 \% ; n=36)$ and also expressed relative to mean zero time datum. Over the same period, i.e. from day 7 to sacrifice, the absolute values for plasma insulin concentration $(\mu \mathrm{U} / \mathrm{ml})$ recorded in the $($ Fsal) rats were also lower $(\mathrm{p}<0.001)$ than those found in (Ssun) animals, averaging in the former rats $75.3 \pm 2.9 \%(n=34)$ of the mean corresponding values found at the same time in the latter control animals $(100.0 \pm 3.6 \%$; $\mathrm{n}=36$ ).
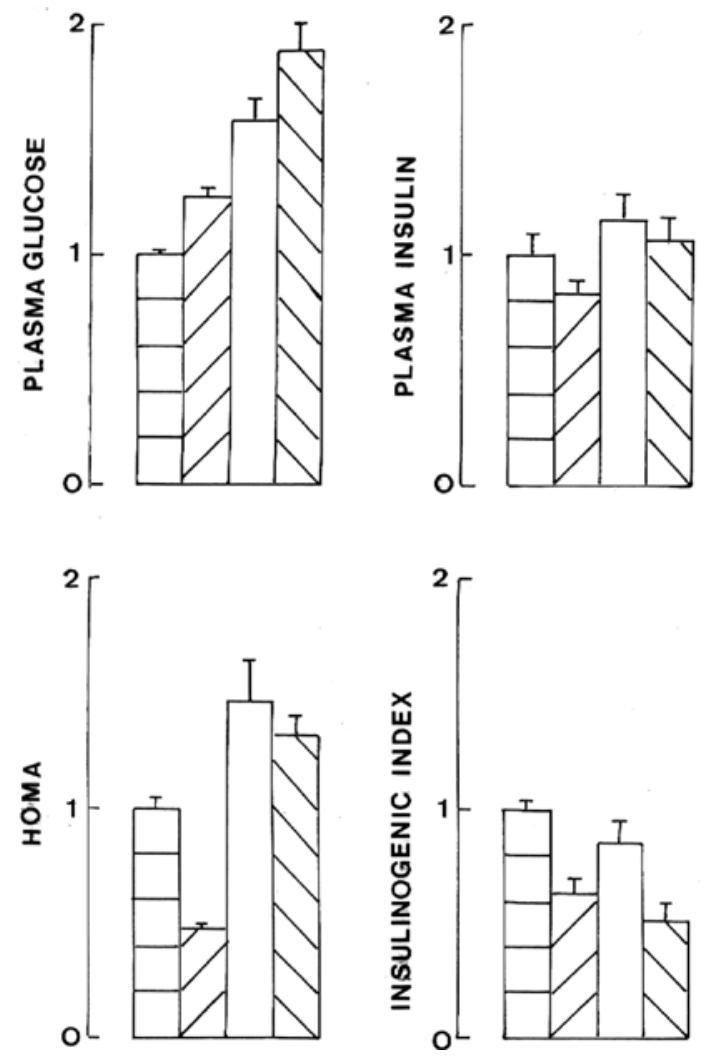

Figure 5. Upper left panel: plasma D-glucose concentrations expressed relative to the mean corresponding value at time zero and recorded between day 7 and sacrifice in (Ssun) rats (horizontally hatched columns), (Fsal) rats (ascending obliquely hatched columns), (Fsun) rats (open columns) and (Fsaf) rats (descending obliquely hatched columns) are shown relative to the mean values recorded at the same time in the (Ssun) rats; mean values ( \pm SEM) refer to 34-36 individual determinations. Upper right panel: absolute values for plasma insulin concentration between day zero and sacrifice are shown relative to the mean value found in (Ssun) rats, mean values ( \pm SEM) refer to 40-42 determinations. Lower left panel: HOMA data presented in the same manner as in the upper left panel; mean values $( \pm$ SEM) refer to 34-36 determinations. Lower right panel: insulinogenic indices recorded between day 14 and sacrifice are presented in the same manner as in the upper left panel; mean values ( \pm SEM) refer to $28-30$ determinations.

In the (Fsun) rats, the insulin concentration expressed relative to the corresponding mean zero time value, represented between day 7 and sacrifice $2-3$ times $(241.7 \pm 19.9 \%$; $n=36)$ the values, expressed on the same manner and recorded at the same time in the (Fsal) rats. Likewise, the absolute values $(\mu \mathrm{U} / \mathrm{ml})$ for plasma insulin concentration between day 7 and sacrifice were significantly higher $(\mathrm{p}<0.001)$ in the (Fsun) rats than in the (Fsal) rats. Such absolute values were also higher $(p<0.07)$ in the former rats than in the (Ssun) animals, the measurements performed in the (Fsun) rats averaging between day 7 and sacrifice $118.0 \pm 8.8 \%(n=36)$ from those recorded at the same time in (Ssun) animals $(100.0 \pm 3.6 \% ; n=36)$. Such a difference already achieved statistical significance $(\mathrm{p}<0.002$ or less) 7 days after the start of the experiments, whether judged from the absolute values for plasma insulin concentrations $(\mu \mathrm{U} / \mathrm{ml})$ or the results expressed relative to the corresponding mean zero time measurements.

In (Fsaf) rats, the plasma insulin concentrations, expressed relative to the corresponding mean zero time, averaged $196.3 \pm 10.6 \%(n=36 ; p<0.001)$ of the mean values found at the 
Table III. Metabolic and hormonal data at sacrifice.

\begin{tabular}{lcccc}
\hline Rats & Ssun & Fsun & Fsal & Fsaf \\
\hline Plasma D-glucose $(\mathrm{mM})$ & $9.76 \pm 0.38(6)$ & $9.33 \pm 0.50(6)$ & $7.33 \pm 0.48(5)$ & $10.20 \pm 0.69(6)$ \\
Plasma insulin $(\mu \mathrm{U} / \mathrm{ml})$ & $25.9 \pm 1.5(6)$ & $27.3 \pm 4.2(6)$ & $23.4 \pm 1.3(5)$ & $32.5 \pm 2.7(6)$ \\
Insulinogenic index $(\mathrm{U} / \mathrm{mol})$ & $4.64 \pm 0.57(6)$ & $5.49 \pm 1.07(6)$ & $7.42 \pm 0.73(5)$ & $5.39 \pm 0.43(6)$ \\
HOMA $(\mathrm{mM} . \mu \mathrm{U} / \mathrm{ml})$ & $252 \pm 12(6)$ & $250 \pm 35(6)$ & $174 \pm 21(5)$ & $339 \pm 47(6)$ \\
Plasma D-fructose $(\mu \mathrm{M})$ & $387 \pm 73(6)$ & $347 \pm 27(6)$ & $350 \pm 24(5)$ & $378 \pm 62(6)$ \\
Glycated hemoglobin $(\%)$ & $5.81 \pm 0.04(6)$ & $13.67 \pm 0.13(6)$ & $8.76 \pm 0.02(5)$ & $12.11 \pm 0.11(6)$ \\
Albumin $(\mathrm{g} / \mathrm{dl})$ & $3.93 \pm 0.02(6)$ & $4.20 \pm 0.02(6)$ & $4.03 \pm 0.02(6)$ & $4.17 \pm 0.02(6)$ \\
\hline
\end{tabular}

same time in the (Fsal) rats $(100.0 \pm 2.8 \% ; n=34)$. Such a difference progressively increased during the experiments, the values found in the (Fsaf) rats, expressed relative to those found at the same time in the (Fsal) rats averaging $149.8 \pm 14.3 \%(n=12)$ on days 4 and $14,205.2 \pm 17.0 \%(n=12)$ on days 21 and 28 , and $233.8 \pm 15.8 \%(n=12)$ on day 35 and at sacrifice. Likewise, the absolute values $(\mu \mathrm{U} / \mathrm{ml})$ for insulin concentrations averaged in the (Fsaf) rats $137.4 \pm 7.4 \%(n=36 ; \mathrm{p}<0.001)$ of the mean corresponding values found at the same time after the start of the experiments in the (Fsal) rats $(100.0 \pm 2.8 \%$; $n=34)$, there being again a significant positive correlation $(\mathrm{p}<0.006)$ between the values recorded in the former (Fsaf) rats expressed relative to those found at the same time in the (Fsal) rats and the time spent after the start of the experiments. Such absolute values were not significantly different $(\mathrm{p}>0.51)$ in the (Fsaf) rats $(68.1 \pm 7.8 \mu \mathrm{U} / \mathrm{ml} ; \mathrm{n}=36)$ and the (Fsal) rats $(75.3 \pm 7.9 \mu \mathrm{U} / \mathrm{ml}$; $\mathrm{n}=36)$.

HOMA for insulin resistance. Before the start of the experiments, the HOMA for insulin resistance, i.e. the product of plasma glucose times plasma insulin concentration, averaged $428.9 \pm 34.9 \mathrm{mM} . \mu \mathrm{U} / \mathrm{ml}(\mathrm{n}=24)$.

In the (Ssun) animals, the mean HOMA after the start of the experiments was not significantly different $(\mathrm{p}>0.21)$ from that recorded at time zero.

As depicted in Fig. 1, at day 7, the HOMA, expressed relative to the mean corresponding value recorded at time zero, was already decreased $(\mathrm{p}<0.02)$ in the $(\mathrm{Fsal})$ rats to $66.8 \pm 5.5 \%(n=6)$ of the reference value found in the (Ssun) animals $(100.0 \pm 9.6 \% ; n=6)$. It then reached in the (Fsal) rats a plateau value representing $42.8 \pm 1.9 \%(n=28)$ of the reference value found at the same time in the (Ssun) rats. The absolute values for the HOMA were also lower $(\mathrm{p}<0.001)$ in the $($ Fsal $)$ rats than in the (Ssun) animals, averaging in the former rats between day 7 and sacrifice $71.8 \pm 3.7 \%(n=34)$ of the mean corresponding values found at the same time in the latter (Ssun) animals $(100.0 \pm 4.6 \% ; \mathrm{n}=36)$.

Between day 7 and sacrifice, the HOMA recorded in the (Fsun) rats, expressed relative to the mean corresponding time zero value, averaged $146.7 \pm 16.9 \%(n=36 ; p<0.01)$ of the reference values found at the same time in the (Ssun) animals $(100.0 \pm 4.6 \% ; n=36)$.

In the (Fsaf) rats, the HOMA values recorded between day 7 and sacrifice and expressed relative to the mean corresponding time zero value averaged $109.0 \pm 7.9 \%(n=36 ; p>0.35)$ of the mean values found at the same time, and expressed in the same manner, in the (Fsun) rats $(100.0 \pm 5.3 \%$; $=36)$. As illustrated in Fig. 4, between day 21 and sacrifice, the HOMA values found in these two groups of rats, always expressed relative to the mean corresponding time zero values, averaged $156.8 \pm 12.7 \%$ $(\mathrm{n}=48 ; \mathrm{p}<0.004)$ of those recorded at the same time in the (Ssun) animals $(100.0 \pm 5.7 \%$; $n=24)$.

Insulinogenic index. The insulinogenic index was calculated assuming a plasma glucose concentration of $4.0 \mathrm{mM}$ as the threshold value for the insulinotropic action of the hexose. It averaged $36.07 \pm 4.08 \mathrm{U} / \mathrm{mol}(\mathrm{n}=24)$ before the start of the experiments.

In the (Ssun) rats, it failed to differ significantly $(\mathrm{df}=40$; $p>0.66$ ) before the start of the experiments and between day 7 and sacrifice.

In the (Fsal) rats, the insulinogenic index, expressed relative to the mean value recorded before the start of the experiments, averaged between day 7 and sacrifice $61.5 \pm 5.4 \% \quad(n=34$; $\mathrm{p}<0.001)$ of the results recorded at the same time and expressed in the same manner in the (Ssun) rats $(100.0 \pm 3.6 \% ; n=36)$. The absolute values $(\mathrm{U} / \mathrm{mol})$ for the same index, as recorded between day and sacrifice, were no more significantly lower ( $\mathrm{p}>0.61$ ), however, in the (Fsal) rats than in the (Ssun) rats, the values recorded in the former rats averaging $95.4 \pm 8.4 \%$ $(n=34)$ of those found at the same time in the latter animals $(100.0 \pm 3.6 \% ; n=36)$.

Between day 14 and sacrifice, the insulinogenic index failed to differ significantly in the (Fsun) rats and (Ssun) animals, whether it was expressed in absolute terms $(p>0.21)$ or relative to the corresponding time zero mean value ( $>0.11)$, the results recorded in the former rats averaging, respectively, $85.7 \pm 10.6 \%$ and $126.0 \pm 15.6 \%$ ( $n=30$ in both cases) of the reference values found at the same time in the latter animals, i.e. $100.0 \pm 3.6 \%$ $(n=30)$.

Over the same period, i.e. between day 14 and sacrifice, the insulinogenic index found in the (Fsaf) rats, when expressed relative to the corresponding time zero value represented $68.4 \pm 6.1 \%(n=30 ; p<0.005)$ of the results collected at the same time in the (Fsun) animals $(100.0 \pm 8.5 \% ; n=30)$. Likewise, the absolute values recorded between day 14 and sacrifice averaged in the former rats $78.2 \pm 7.0 \%(n=30 ; p<0.06)$ of the results collected at the same time in the latter animals $(100.0 \pm 8.5 \%$; $\mathrm{n}=30$ ). Fig. 5 documents some of the most relevant findings collected in these experiments. 
Metabolic and hormonal data. The percentage of glycated hemoglobin was twice higher $(\mathrm{p}<0.001)$ in (Fsun) rats than in (Ssun) rats. It was slightly lower $(\mathrm{p}<0.05)$ in (Fsaf) rats than (Fsun) rats, and markedly lower $(\mathrm{p}<0.001)$ in (Fsal) rats than in (Fsun) rats (Table III).

At sacrifice, i.e. after overnight starvation, the plasma D-fructose concentration was comparable ( $p>0.6$ or more) in all four groups of rats.

The plasma albumin concentration was higher $(\mathrm{p}<0.001)$ in the fructose-fed rats $(4.14 \pm 0.02 \mathrm{~g} / \mathrm{dl} ; \mathrm{n}=17)$ than in the (Ssun) rats $(3.93 \pm 0.02 \mathrm{~g} / \mathrm{dl} ; \mathrm{n}=6)$.

\section{Discussion}

The present study affords several novel pieces of information: First, it documents a decrease of food intake by fructose-fed, as distinct from starch-fed, rats, such a decrease being even more pronounced after partial substitution of sunflower oil by either $\omega 3$-rich salmon oil or C18:2 $\omega 6$-rich safflower oil. Second, it reveals that, despite lower food intake, the fructose-fed rats displayed a higher gain in body weight than the control animals exposed to the starch-containing diet. The factor(s) responsible for this unexpected situation are open to speculation. Obviously, it cannot be attributed to possible glycosuria in the most severely hyperglycemic rats. It also could not be attributed to any increase in the mass of adipose tissue in the fructose-fed rats. On the contrary, the weight of both parametrial and visceral adipose tissue was lower in the fructose-fed rats than in the starch-fed rats, at least when both exposed to diets containing the same amount of sunflower oil. The sole possible indication of cell steatosis in the fructose-fed rats consisted in an increase of both liver and kidney weight. It could be objected, however, that such an increase was no more observed when the weight of liver and kidney were expressed relative to body weight. Thus, relative to body weight, the kidney weight averaged $3.53 \pm 0.08 \%$ o $(\mathrm{n}=6$ ) in (Ssun) rats, $3.62 \pm 0.22 \%$ o $(n=6)$ in (Fsun) rats, $3.83 \pm 0.27 \%$ $(\mathrm{n}=5)$ in (Fsal) rats and $3.70 \pm 0.17 \%$ o $(\mathrm{n}=6)$ in (Fsaf) rats, none of these values being significantly different from one another. Likewise, relative to body weight, the heart weight averaged $26.9 \pm 0.6 \%$ o $(n=6)$ in (Ssun) rats, $25.7 \pm 0.7 \%$ o $(n=6)$ in (Fsun) rats, $28.2 \pm 1.7 \%$ in $(n=5)$ in (Fsal) rats and $31.0 \pm 0.9 \%(n=6)$ in (Fsaf) rats. Only the latter value remained significantly higher $(\mathrm{p}<0.005)$ from that found in either (Ssun) or $(\mathrm{Fsal})$ rats. Although the dissociated changes in food intake and body weight could conceivably represent an uncommon situation, e.g. restricted to $\omega 3$-depleted rats, it cannot be solely attributable to a difference in the dietary supply of long-chain polyunsaturated $\omega 3$ fatty acids, being also observed when comparing starch-fed and fructose-fed rats both exposed to the same $\omega 3$-poor sunflower oil-containing diet.

Second, it documents time-related changes in plasma D-glucose and insulin concentrations, as well as insulinogenic and HOMA indices. In this respect, there was a fair agreement between the present findings, as illustrated in Fig. 5, and those recorded at time sero of the IPGTT conducted in the same animals (1). First, the plasma D-glucose concentrations displayed the same hierarchy in these two sets of measurements, with the lowest mean value in the (Ssun) rats and the higher mean value in the (Fsaf) rats, with in-between values in the (Fsun) and (Fsal) rats. Second, the plasma insulin concentration displayed in both sets of measurements the highest mean values in (Fsun) rats. Moreover, the overall mean values recorded in the other three groups of rats, expressed relative to those recorded in the (Fsun) rats were comparable $(p>0.48)$ in the two sets of experimental data and indeed significantly lower $(\mathrm{p}<0.03)$ than the reference value found in the (Fsun) rats. Third, the insulinogenic index yielded, in both sets of data, the highest mean value in (Ssun) rats and the lowest mean value in (Fsaf) rats. Even the mean values for the insulinogenic index found in the (Fsun) and (Fsal) rats were, in both sets of data, somewhat lower than that recorded in the (Ssun) rats and significantly higher ( $<<0.02$ or less) than that recorded in the (Fsaf) rats. Last, the HOMA for insulin resistance yielded, in both sets of data, the highest mean values in the (Fsun) and (Fsaf) rats, largely in excess ( $\mathrm{p}<0.01$ or less) of those recorded in the (Ssun) rats. Moreover, in both sets of data, the mean HOMA found in the (Fsal) rats was lower than that recorded in the other two groups of fructose-fed animals, the relative magnitude of such a difference being comparable ( $>0.18)$ in both sets of data and indeed achieving overall statistical significance $(\mathrm{p}<0.001)$.

As expected, at sacrifice, the percentage of glycated hemoglobin was much higher in the (Fsun) and (Fsaf) rats than in the (Fsal) rats, and further decreased in the (Ssun) rats. After overnight starvation, the plasma $\mathrm{D}$-fructose concentration was comparable in the four groups of rats.

In conclusion, the present study reveals a rather unexpected and, in the limits of our knowledge, uneasy to explain dissociation between changes in food intake and body weight, when comparing starch-fed to fructose-fed rats. It also documents obvious differences, in the fructose-fed rats, in terms of glucose homeostasis, insulin resistance and insulinogenic index, as a function of the dietary supply of long-chain polyunsaturated $\omega 3$ and $\omega 6$ fatty acids. The latter difference concerning the insulinogenic index calls for further investigations to be conducted in vitro in islets isolated from the same animals. These investigations are precisely the main matter of the two following report in this series.

\section{Acknowledgments}

We are grateful to C. Demesmaeker for secretarial help.

\section{References}

1. Mellouk Z, Hachimi Idrissi T, Louchami K, Hupkens E, Malaisse WJ, Ait Yahia D and Sener A: The metabolic syndrome of fructose-fed rats: effects of long-chain polyunsaturated $\omega 3$ and $\omega 6$ fatty acids. I. Intraperitoneal glucose tolerance test. Int J Mol Med 28: 1087-1092, 2011.

2. Lowry OH and Passonneau B: A Flexible System of Enzymatic Analysis. Academic Press, New York, pp174-177, 1972. 